Journal of Healthcare Technology and Medicine Vol. 6 No. 2 Oktober 2020

Universitas Ubudiyah Indonesia

e-ISSN : 2615-109X 1127

\title{
ANALISIS PEMANFAATAN PELAYANAN KESEHATAN PEDULI REMAJA (PKPR) DI WILAYAH KERJA PUSKESMAS LANGSA KOTA TAHUN 2020
}

\author{
Analysis Of Health Services Care Utilization For Youth (Pkpr) In \\ Working Areas Langsa Health Centre 2020
}

\author{
Mite Delita Ayu ${ }^{1}$, Achmad Rifai ${ }^{2}$, Elvi Era Liesmayani ${ }^{3}$ \\ 1,2,3 Institut Kesehatan Helvetia, Jl. Kapten Sumarsono No. 107, Medan 20124 \\ ayumite87@gmail.com ${ }^{1}$, achmadrifai10jan@gmail.com ${ }^{2}$, viedylovevy@gmail.com ${ }^{3}$
}

\begin{abstract}
Abstrak
PKPR (Pelayanan Kesehtatan Peduli Remaja) merupakan salah satu strategi pemerintah untuk menyelesaikan masalah kesehatan reproduksi remaja, dijalankan puskesmas sejak tahun 2003. Tujuan penelitian ini untuk menganalisis penyebab rendahnya pemanfaatan PKPR diwilayah kerja puskesmas Langsa Kota.

Penelitian ini menggunakan desain kualitatif, dengan menggunakan metode wawancara mendalam (indepth interview). Pengambilan sample dengan tehnik Purposif Sampling. Informan penelitian terdiri dari 4 orang informan utama remaja tingkat SMP dan 4 orang Informan pendukung. Pengumpulan data dilaksanakan pada bulan Februari-Oktober 2020.

Hasil penelitian menunjukkan bahwa faktor paling dominan dirasakan informan utama tidak memanfaatkan PKPR di wilayah kerja Puskesmas Langsa Kota yaitu kurangnya pengetahuan remaja tentang adanya PKPR dikarenakan lemahnya manajemen puskesmas dalam bentuk kerjasama lintas sektor dan banyak temuan-temuan lainnya yang didapat dari penelitian ini.

Saran kepada pemerintah setempat agar dapat serius dalam membangun generasi masa depan bangsa yang berkualitas, kepada dinas kesehatan agar melakukan evaluasi manajemen PKPR minimal setahun sekali dan menjalankan posyandu remaja, kepada dinas pendidikan agar memberi jam kelas kepada guru BK dan puskesmas dapat membuat inovasi terbaru sesuai dengan keadaan pandemi covid 19 sekarang ini.
\end{abstract}

Kata Kunci : PKPR, Puskesmas dan Remaja

Daftar Pustaka : 15 Buku, 32 Kutipan Internet dan 16 jurnal (2012-2020)

\begin{abstract}
PKPR (Youth Care Health Services) is one of the government's strategies to solve adolescent reproductive health problems, which has been run by puskesmas since 2003. The purpose of this study is to analyze the causes of the low utilization for youth (PKPR) in working areas Langsa Health Centre 2020.

This study used a qualitative design, using the in-depth interview method, conducted in February-October 2020. The informants consisted of 4 main informants for junior high school level adolescents and 4 supporting informants. Sampling used purposive sampling technique.
\end{abstract}


Journal of Healthcare Technology and Medicine Vol. 6 No. 2 Oktober 2020

Universitas Ubudiyah Indonesia

e-ISSN : 2615-109X 1128

The results showed that the most dominant factor felt by the main informant did not take advantage of PKPR in Langsa Health centre, namely due to a lack of knowledge of knowledge of adolescents about the existence of PKPR due to weak management of the health centre in the form of cross-sector cooperation and many other findings of this research.

It is suggested to local government to be serious in building a quality future generation of the nation, to the health office to evaluate PKPR management at least once a year and to run a youth Posyandu, to the education office to provide class hours for counselling teachers and health centre to make the latest innovations the current state of the covid 19 pandemics.

Keywords : :PKPR, Puskesmas and Adolescents

Bibliography : 15 Books, 32 Internet citations and 16 journals (2012-2020)

\section{PENDAHULUAN}

Derasnya arus globalisasi berkembang pula masalah kesehatan remaja baik fisik, psikis maupun psikososial yang berdampak pada kesehatan reproduksi. Namun kelompok remaja sering dianggap tidak bermasalah dibidang kesehatan karena rendahnya angka kesakitan dan kematian. Lambat laun disadari bahwa masalah kesehatan remaja berakar pada masalah psikososial, seperti kehamilan usia muda, perilaku berisiko, penyalahgunaan NAPZA dan kurangnya keterampilan sosial dikalangan remaja. Masalah tersebut apabila tidak ditanggulangi, bukan hanya menyebabkan masa depan remaja menjadi suram, akan tetapi menghambat cita-cita bangsa menuju Indonesia yang bermartabat.

Sejak pertengahan 1970-an World Health Organization (WHO) telah secara aktif terlibat dalam promosi kesehatan remaja, khususnya dalam hal kesehatan reproduksi remaja. Hampir separuh remaja (47\%) menginginkan untuk mendapatkan layanan kesehatan di sekolah (1).

Salah satu negara benua di Afrika bagian selatan yang berhasil menjalankan program Youth-Friendly Health Services (YFHS) adalah Bostwana, stakeholder dari Kementerian Kesehatan \& Kebugaran Ministry Of Health \& Wellness (MOHW) Botswana banyak berperan serta dalam rencana pembangunan nasional yang diinvestasikan pada remaja melalui program peduli remaja sehingga angka capaian keberhasilan program peduli remaja di Bostwana sebesar 95\% (2).

South-East Asia Region (SEAR) (2018-2022) bekerja sama dengan banyak negara anggota dalam program kesehatan remaja yang berada pada tingkat 
Journal of Healthcare Technology and Medicine Vol. 6 No. 2 Oktober 2020

Universitas Ubudiyah Indonesia

e-ISSN : 2615-109X 1129

implementasi. Negara yang memiliki fasilitas kesehatan menerapkan layanan kesehatan ramah remaja Adolescent-Friendly Health Services (AFHS) yaitu Bangladesh, Butan, Indonesia, Maladewa, Myanmar dan Nepal. Negara Indonesia diberikan paket pelatihan khusus kesehatan konseling sebagai bonus negara yang menerapkan pelayanan kesehatan ramah remaja (3). Amerika Serikat mengapresiasi mengapresiasi Program Pelayanan Kesehatan Peduli Remaja (PKPR) di Indonesia pada pertemuan Partnership for Maternal, Newborn and Child Health (PMNCH) yang diselenggarakan di New York tahun 2019 (4)

Pendidikan seksual seharusnya menjadi bagian pendidikan anak disekolah maupun dirumah sejak dini konsepnya berorientasi pada unsur anatomi, fungsi, tata nilai dan sikap kepribadian sehubungan dengan kepemilikan organ reproduksi juga untuk mempersiapkan remaja agar mampu membawakan peran gender organ reprduksinya secara matang. Jika pendidikan seksual diberikan secara benar, tidak ada yang menyimpang dari nilai-nilai ketimuran/adat istiadat, orangtua atau guru harus memiliki nilai-nilai (etika) yang ditanamkan pada remaja, tanpa pembekalan ini remaja justru tidak memiliki kendali bagaimana menjadi orang dewasa yang bertanggungjawab terhadap kesehatan reproduksinya (5).

Salah satu pertanyaan yang sering dipertanyakan adalah apakah wajar remaja membicarakan seks, jawabannya tergantung individu masing-masing, jika seks dibicarakan untuk tujuan mulia bukan sesuatu hal yang porno. Misalnya dalam perkumpulan remaja dibicarakan bagaimana kiat menjaga diri dari segala bentuk pelecehan seks. Saat ini sekolah sudah memasukkannya dalam mata pelajaran dengan tujuan untuk memberikan pengetahuan tentang bahaya-bahaya yang ditimbulkan akibat persepsi seks yang salah (5).

Kementerian Kesehatan RI telah mengembangkan Program Kesehatan Remaja dengan pendekatan Pelayanan Kesehatan Peduli Remaja (PKPR) sejak tahun 2003, salah satu strategi pemerintah yang menitik beratkan kegiatan dalam bentuk penyuluhan dan konseling untuk menyelesaikan masalah terkait kesehatan reproduksi remaja, kata "peduli remaja" disini bertujuan agar remaja tidak menganggap hanya kesehatan reproduksi, tetapi perilaku beresiko terhadap 
Journal of Healthcare Technology and Medicine Vol. 6 No. 2 Oktober 2020

Universitas Ubudiyah Indonesia

e-ISSN : 2615-109X 1130

kesehatan juga ditangani sehingga remaja terbuka dengan masalah kesehatannya (4).

Besarnya penduduk remaja akan berpengaruh pada pembangunan dari aspek sosial, ekonomi, maupun demografi baik saat ini maupun dimasa yang akan datang. Mereka sangat beresiko terhadap masalah- masalah kesehatan reproduksi yaitu perilaku seksual pra nikah, Narkoba Psikotropika dan Zat adiktif lainya (NAPZA) dan HIV/AIDS (9).

Menanggapi isu demografi yang dialami oleh remaja Indonesia bukan tanpa tantangan masih ada permasalahan yang mengancam remaja, terutama yang terkait pada kesehatan reproduksi dan gizi yang akan berdampak pada kualitasnya sebagai faktor pembangunan dan kesiapanya dalam membangun keluarga. Pubertas/ kematangan seksual yang semakin dini (aspek internal) dan aksesibilitas terhadap berbagai media serta pengaruh negatif sebaya (aspek external) menjadikan remaja rentan terhadap perilaku seksual berisiko salah satu aspek utamanya mengenai remaja hamil di luar nikah atau dapat disebut dengan Kehamilan yang Tidak diinginkan (KTD) (10).

Dibuktikan dari hasil penelitian Kasim F (2014) menunjukkan bahwa praktik seks berisiko di Aceh tertinggi terjadi di Kota Lhokseumawe, dengan tingkat keterlibatan pelajar mencapai 70 persen. Lhokseumawe menduduki peringkat pertama terbanyak pelaku seks pra-nikah di kalangan pelajar, menyusul Banda Aceh. Dampak dari seks berisiko adalah kasus kehamilan tidak diinginkan, penyakit kelamin menular, HIV/AIDS, serta aspek psikologi dan sosial lainya (14).

Terjadi peningkatan tren kasus HIV pada remaja sebesar $20 \%$ dalam Profil Dinas Kesehatan kota Langsa tahun 2019, sedangkan tahun 2017 sebesar 0\% (tidak ada kasus). Menurut penanggung jawab PKPR Program dan poli PKPR di puskesmas Langsa Kota sudah ada sejak kurang lebih tahun 2010. Rekapan laporan kunjungan remaja sakit ke puskesmas tahun 2019 sebanyak 1.395 kunjungan dari 8.764 jiwa jumlah remaja di wilayah kerja puskesmas langsa kota (15). Hanya 52 remaja (3\%) dari jumlah kunjungan remaja yang datang kepuskesmas) untuk konseling dalam satu tahun terakhir. Temuan kasus kehamilan usia remaja 
Journal of Healthcare Technology and Medicine Vol. 6 No. 2 Oktober 2020

Universitas Ubudiyah Indonesia

e-ISSN : 2615-109X 1131

dipuskesmas Langsa Kota tahun 2019 sebanyak 13 kasus, 2 diantaranya berada pada masa remaja pertengahan (SMP). Sebagian besar kunjungan remaja dengan masalah kesehatan fisik (16).

Observasi awal peneliti berupa wawancara kepada penanggung jawab ruang poli PKPR Puskesmas Langsa Kota yaitu “Tidak adanya pasien/remaja yang sukarela datang untuk konseling tentang masalah kesehatan reproduksi atau perilaku beresikonya atas keinginan sendiri mungkin penyebabnya dirasa ruangan kurang nyaman untuk berkonsultasi”. Dibuktikan dari survey awal peneliti ke salah satu sekolah dalam wilayah kerja puskesmas Langsa Kota yang berada dekat dengan puskesmas Langsa kota yaitu di SMPN 5 kepada salah seorang siswi yang mengatakan bahwa petugas kesehatan hanya memberikan vitamin saja, ada diberikan penyuluhan kesehatan secara pribadi tetapi lupa seperti apa.

\section{METODE PENELITIAN}

Penelitian ini menggunakan desain penelitian kualitatif dengan pendekatan studi kasus dimana metode yang digunakan adalah metode wawancara mendalam (indepth interview). Penelitian kualitatif bertujuan untuk mendapatkan pemahaman yang mendalam tentang masalah-masalah manusia dan sosial, bukan mendeskripsikan bagian permukaan dari suatu realitas sebagaimana dalam penelitian kuantitatif dengan positismenya (17).

Penelitian ini tidak memberikan perlakuan, manipulasi atau pengubahan pada variabel yang diteliti melainkan menggambarkan suatu kondisi apa adanya. Oleh karena itu penelitian kualitatif merupakan rangkaian kegiatan memperoleh data yang bersifat apa adanya tanpa dalam kondisi tertentu yang hasilnya lebih menekankan makna (18).

Peneliti berusaha menggali informasi sedalam-dalamnya tanpa berusaha mengganggu ataupun mempengaruhi pemikiran informan. Peneliti tidak hanya mengetahui berbagai fakta yang mendasari kurangnya pemanfaatan PKPR oleh remaja di wilayah kerja Puskesmas Langsa Kota tahun 2020, namun juga mencari tahu lebih dalam serta mengevaluasi program PKPR di puskesmas Langsa Kota. 
Journal of Healthcare Technology and Medicine Vol. 6 No. 2 Oktober 2020

Universitas Ubudiyah Indonesia

e-ISSN : 2615-109X 1132

Peneliti bertindak sebagai instrumen sekaligus pengumpul data. Peneliti menggunakan observasi yang mana dalam pengumulan data ini peneliti berinteraksi secara langsung dengan informan namun peneliti tidak terlibat secara langsung dalam kegiatan informan. Kehadiran peneliti mutlak diperlukan karena peneliti merupakan instrumen kunci. Sesuai dengan permasalahan yang dihadapi dilapangan maka kehadiran peneliti diketahui statusnya oleh subjek atau informan sebagai peneliti. Sedangkan peran peneliti sebagai pegamat penuh (18).

Adapun lokasi yang digunakan dalam penelitian ini adalah sekolah tingkat SMP di wilayah kerja Puskesmas Langsa Kota. Waktu penelitian dilakukan dari bulan Februari - September 2020.

Pengambilan sample penelitian ini menggunakan nonprobability sampling dengan tehnik Purposif Sampling. Pemilihan informan pada penelitian kualitatif sepenuhnya ditentukan oleh peneliti, sehingga Patton (2002) menyebutnya dengan purposeful sampling, yaitu memilih kasus yang informatif (information-rich cases) berdasarkan strategi dan tujuan yang telah ditetapkan peneliti, yang jumlahnya tergantung pada tujuan dan sumberdaya studi (19).

Informan penelitian ini terdiri dari Informan Utama 4 orang remaja SMP dari sekolah yang berbeda-beda (2 laki-laki dan 2 perempuan), Informan pendukung terdiri dari 4 orang yaitu kepala Puskesmas, penanggung jawab program PKPR, Kepala UKS dan guru BK.

Tehnik keabsahan data yaitu triangulasi digunakan sebagai proses memantapkan derajat kepercayaan (validitas) dan konsisten (reabilitas) data serta alat bantu analisis data dilapangan. Bila peneliti melakukan pengumpulan data dengan triagulasi maka sebenarnya peneliti mengumpulkan data sekaligus menguji kredibilitas data (51).

Tehnik pemeriksaan keabsahan data yang digunakan dalam penelitian ini adalah triangulasi dengan sumber. Pengecekan data kembali dilakukan dengan cara membandingkan sumber satu dengan sumber yang lain yang diperoleh dari informan utama dan informan pendukung (18). 
Journal of Healthcare Technology and Medicine Vol. 6 No. 2 Oktober 2020

Universitas Ubudiyah Indonesia

e-ISSN : 2615-109X 1133

\section{HASIL DAN PEMBAHASAN}

Kegiatan wawancara mendalam informan utama dan informan triagulasi waktu dan tempat sesuai dengan keinginan informan dilakukan di rumah responden, di sekolah, di cafe dan beberapa informan melalui online.

\section{Faktor Manusia (SDM)}

a. Pengetahuan informan utama

Hasil penelitian menunjukkan bahwa tingkat pengetahuan informan utama khususnya kegiatan konseling kesehatan reproduksi remaja program PKPR sangat kurang sehingga mereka tidak memanfaatkan PKPR. Temuan didapat dari penelitian ini adalah petugas kesehatan atau pihak sekolah tidak pernah memberi tahu adanya PKPR artinya adanya keterkaitan pengetahuan tentang adanya sarana PKPR terhadap pemanfaatan PKPR.

Adapun pengetahuan dan keterampilan petugas PKPR yang harus dimiliki yaitu Tumbuh Kembang Remaja, Kesehatan Reroduksi Remaja (KRR), IMS/ISR, HIV/AIDS, Penyalahgunaan NAPZA, Pengenalan Konsep Gender, Pendidikan Keterampilan Hidup Sehat (PKHS), Tehnik Konseling Kesehatan Remaja dan Jejaring dalam PKPR. Serta wawasan petugas PKPR tentang strategi nasional kesehatan remaja dan pedoman PKPR di Puskesmas (25).

Serupa dengan penelitian yang dilakukan oleh Yunita K (2017) yaitu petugas kesehatan yang bersahabat memberikan kesempatan remaja untuk memanfaatkan pelayanan kesehatan reproduksi 8 kali lebih besar dibandingkan dengan petugas yang kurang bersahabat. Hasil dari penelitian ditemukan variabel yang paling mempengaruhi pemanfaatan kesehatan reproduksi remaja yaitu petugas yang bersahabat. Adanya petugas yang tidak bisa menjaga rahasia, sehingga remaja tidak merasa nyaman dalam mengungkapkan permasalahannya. Kondisi tersebut membuat remaja tidak datang ke layanan PKPR untuk memanfaatkan fasilitas (27).

Menurut peneliti, diperlukan peran petugas kesehatan khusunya penanggung jawab PKPR dalam mengaktifkan program PKPR. Penyegaran tentang tugas dan fungsi petugas kesehatan dalam PKPR perlu dilakukan. Sesuai dengan 
Journal of Healthcare Technology and Medicine Vol. 6 No. 2 Oktober 2020

Universitas Ubudiyah Indonesia

e-ISSN : 2615-109X 1134

tugas dan fungsi tenaga kesehatan di puskesmas dalam permenkes No.75/2014 upaya kesehatan masyarakat danUU RI No 36/2014 yaitu tenaga kesehatan merupakan setiap orang yang mengabdikan diri dalam bidang kesehatan serta memiliki pengetahuan dan keterampilan melalui pendidikan di bidang kesehatan untuk jenis tertentu yang memerlukan kewenangan dalam melakukan upaya kesehatan.

\section{Faktor Metode (Upaya)}

a. Manajemen PKPR

Hasil wawancara mendalam didapatkan bahwa seluruh informan utama mengatakan tidak ada konselor sebaya dan petugas tidak pernah melakukan konseling disekolah.

Temuan peneliti didapatkan tidak adanya kerja sama secara khusus antara puskesmas dengan sekolah dalam kegiatan penyuluhan, konseling dan pembinaan konselor sebaya sebagai upaya promotif preventif puskesmas. Kegiatan konseling disekolah hanya dilakukan oleh guru BK, tetapi tidak ada remaja yang sukarela datang untuk konsultasimenanyakan masalah yang berhubungan dengan kesehatan reproduksinya. Sehingga terkesan kegiatan konseling tentang kesehatan reproduksi tidak dilakukan.

Jejaring kesehatan remaja adalah suatu jaringan kerjasama aktif berbagai pihak yang meliputi lintas program, lintas sektoral seperti sektor pendidikan, organisasi dan lainya yang ditujukan untuk mengatasi masalah kesehatan remaja di wilayah tertentu (25).

Manajemen pelaksanaan PKPR di puskesmas menurut kemenkes RI 2015, terdiri dari pelayanan dalam gedung dimulai dari pasien datang melalui loket, langsung diregister di ruang PKPR, dianamnesa masalah yang dihadapi,apabila tidak perlu pelayanan medis pasien bisa langsung pulang, pasien yang memerlukan pelayanan klinis medis/lab dengan kasus kehamilan, pemeriksaan infeksi saluran reproduksi, kontrasepsi dan konseling lanjutan.

Puskesmas Langsa Kota tidak memiliki MOU khusus PKPR, pelayanan luar gedung UK, berupa upaya preventif yaitu pelayanan gizi pada remaja putri termasuk edukasi (KIE), pemberian Tablet Tambah Darah (TTD) dan pemeriksaan 
Journal of Healthcare Technology and Medicine Vol. 6 No. 2 Oktober 2020

Universitas Ubudiyah Indonesia

e-ISSN : 2615-109X 1135

kesehatan berkala setahun sekali. Tidak adanya penyuluhan,pelayanankonseling pada semua remaja yang kontak dengan petugas PKPR dan pembinaan konselor sebaya, sehingga mengakibatkan remaja tidak dilibatkan dalam pengembangan dan pelaksanaan PKPR yang mengakibatkan rendahnya pemanfaatan PKPR dipuskesmas Langsa Kota.

Sejalan dengan penelitian yang dilakukan oleh Indah M (2017) mengatakan hambatan yang ditemui dalam pelaksanaan PKPR adalah masalah terkait lemahnya manajemen PKPR dan keterbatasan SDM agar pemerintah menunjukkan keseriusan dalam membangkitkan program $\operatorname{PKPR}(28)$.

Menurut peneliti tidak adanya kerja sama advokasi khusus antara puskesmas dengan sekolah dalam hal penyuluhan, konseling dan pelatihan konselor sebaya dikarenakan lemahnya menejemen puskesmas. Terlihat dari belum lengkapnya Standar dan pedoman penyelenggaraan PKPR, Belum optimalnya sistem manajemen PKPR (Pencatatan, Pelaporan, Evaluasi dan pemantauan)

Serupa dengan penelitian Sri S (2019) yaitu adanya kebijakan dari pemerintahan di Kota Bukittinggi dan berjasama dengan semua Lintas Sektor dalam memberikan penyuluhan kesehatan agar pelaksanaan program ini berjalan maksimal(29).

Menurut peneliti,tidak adanya sosialisasi adanya PKPR dipuskesmas agar bisa dimanfaatkan oleh remaja sebagai upaya promotif puskesmas sangat mempengaruhi terlaksananya upaya kesehatan oleh remaja, sehingga terkesan puskesmas hanya sekedar mengerjakan upaya kesehatan sebagai formalitas saja.

\section{Faktor Material (Sarana)}

Hasil wawancara mendalam didapatkan bahwa seluruh informan utamamengatakan tersedia ruangan untuk konsultasi disekolah, sarana PKPR seperti peralatan medis atau media informasi di sekolah belum lengkap.Hasil temuan didapatkan informan utamatidak fokus ke dalam bentuk fisik/benda seperti meja, tempat tidur, timbangan stetoskop dan lainnya. 
Journal of Healthcare Technology and Medicine Vol. 6 No. 2 Oktober 2020

Universitas Ubudiyah Indonesia

e-ISSN : 2615-109X 1136

Seluruh infforman mengatakan menginginkan ruangan yang dapat menjaga privasi dengan suasana ruangan yang menyenangkan. Artinya belum ada ruang konseling disekolah yang menurut remaja nyaman.

Hasil wawancara mendalam juga didapat dari 4 orang informan utama 3 orang informan mengatakan akses untuk mendapatkan PKPR dirasakan jauh, sehingga diperlukan aktifasi PKPR di sekolah agar tidak menjadi kendala remaja untuk bisa menjangkau sarana kesehatan.

Sejalan dengan penelitian yang dilakukan oleh Kenti F, (2016) yaitu Pelaksanaan program PKPR di Jakarta belum memenuhi kriteria pelayanan remaja seperti yang ditetapkan karena belum cukupnya sarana prasarana, perlu perluasan sosialisasi PKPR dan dukungan pemerintahan daerah di masing-masing wilayah kerja puskesmas(30).

Ruangan konseling dan pemeriksaan: adanya ruang yang dapat digunakan untuk melakukan pemeriksaan/konseling yang menjamin kerahasiaan klien, bersih dan tidak berbau.Perlengkapan dalam ruangan: Pada ruang yang digunakan untuk melakukan pemeriksaan/konseling terdapat meja, kursi, karpet dalam kondisi yang baik.Peralatan medik (yang dimiliki puskesmas): Timbangan berat badan dan tinggi badan, stetoskop, termometer, tensimeter.

Media KIE dan konseling (yang dimiliki puskesmas): brosur, lembar balik, poster, tabel IMT. Pedoman dan Referensi:Pedoman penyelenggaraan PKPR di puskesmas, Pedoman penyelengaraan pelatihan PKPR, Pedoman Standar Nasional PKPR, Modul pelatihan PKPR.

Menurut peneliti, sarana dikatakan tersedia dan terjangkau jika memiliki material ruangan konseling/pemeriksaan yang dapat dimanfaatkan oleh remaja dengan mudah dengan tidak mengganggu jam sekolah. Maka diperlunya aktifasi program PKPR di sekolah agar tidak menjadi kendala untuk remaja terkait jarak yang sulit ditempuh bagi remaja.

\section{Faktor Lingkungan}

a. Syariat Islam

Hasil wawancara mendalam didapatkan bahwa seluruh informan utama mengatakan membicarakan kesehatan reproduksi tidak sesuatu hal yang tabu 
Journal of Healthcare Technology and Medicine Vol. 6 No. 2 Oktober 2020

Universitas Ubudiyah Indonesia

e-ISSN : 2615-109X 1137

namun masih dianggap tabu oleh sebagian orang karena jarang dibicarakan dilingkungannya. Hal ini sesuai dengan temuan yang didapatoleh peneliti yaitu orang tua siswa takut anaknya menjadi responden setelah peneliti membicarakan terkait masalah kesehatan reproduksi tentang pernahkah mengalami masalah kesehatan reproduksi dalam 1 tahun terakhir.

Puskesmas Langsa Kota berada di wilayah yang kental dengan Syariat Islam. Penetapan Qanun Aceh no.4 tentang kesehatan, pasal 64 ayat (1) yaitu setiap anak usia sekolah dan remaja berhak atas informasi dan edukasi serta layanan kesehatan termasuk kesehatan reproduksi remaja, NAPZA serta HIV/AIDS agar terbebas dari berbagai gangguan kesehatan dan penyakit yang dapat menghambat perkembangannya. Hak tersebut menjadi tanggung jawab dan kewajiban bersamaAceh, Kabupaten/Kota, swasta dan masyarakat.

Dimulai dengan disahkannya Undang-Undang no. 44 tahun 1999 tentang penyelenggaraan keistimewaan provinsi Daerah Istimewa Aceh yang menegaskan bahwa status keistimewaan Aceh terletak pada "kewenangan khusus untuk menyelenggarakan kehidupan beragama, adat, pendidikan dan ulama dalam penetapan kebijakan daerah".

Menurut ketua Perkumpulan Keluarga Berencana Indonesia(PKBI), Sarsanto Wibisono Sarwono, selama ini ada penolakan untuk memasukkan kesehatan reproduksi ke dalam kurikulum pendidikan dasar hingga menengah. Pendidikan kesehatan reproduksi yang disisipkan dalam mata pelajaran biologi dan pendidikan kesehatan jasmani tidak cukup bagi anak-anak sekolah.Secara konsep ini sudah diberikan dalam pendidikan biologi, tapi masuk dalam kurikulum itu penting. Kita bisa melihat pada kejadian akhir-akhir ini, penularan HIV dulu usia pekerja, kini ke SMP dan SMA, penggunaan narkoba, kehamilan yang tidak diinginkan, kekerasan seksual, kalau tidak segera dimasukkan, akan seperti gunung es makin lama makin besar, kita harus potong mata rantainya (33).

Praktik pemberian materi kesehatan reproduksi ini masih dianggap tabu oleh sebagian kalangan guru dan orangtua. Pemberian materi kesehatan reproduksi di sekolah penting, karena sebagian besar remaja menghabiskan waktu sehari-hari 
Journal of Healthcare Technology and Medicine Vol. 6 No. 2 Oktober 2020

Universitas Ubudiyah Indonesia

e-ISSN : 2615-109X 1138

di sekolah, sementara orang tua belum tentu memahami bagaimana cara memberikan informasi pendidikan seks kepada anak-anak (33).

Menurut peneliti diperlukan dukungan sekolah dalam bentuk kerja puskesmas. Sudah menjadi tugas seorang guru untuk mengembangkan potensi yang dimiliki remaja agar remaja dapat mandiri dan berkembang menjadi manusiamanusia yang cerdas, secara fisik, intelektual, sosial. Sekolahmerupakan lingkungan kedua yang dikenal remaja setelah keluarga. Tidak adanya dukungan dari sekolah juga akan membuat siswa kurang percaya diri, tidak mendapat bantuan yang sistematis. Maka dari itu PKPR membutuhkan kerja sama lintas sektoral berupa dukungan dari sekolahagar remaja dapat mendapatkan pelayanan kesehatan yang menyeluruh.

\section{KESIMPULAN DAN SARAN}

Berdasarkan Penelitian yang dilakukan pada bulan Februari sampai September 2020, bertujuan untuk menganalisis pemanfaatan PKPR di wilayah kerja puskesmas Langsa Kota tahun 2020 dengan jumlah informan 8 orang dapat disimpulkan: Hal yang melatar belakangi kurangnya pengetahuan remaja yaitu lemahnya manajemen puskesmas dalam bentuk kerjasama lintas sektor antara puskesmas dengan sekolah. Hal ini dibuktikan dari hasil wawancara mendalam seluruh informan utama dan analisis triangulasi didapat bahwa belum optimalnya manajemen PKPR (Pencatatan, Pelaporan, Evaluasi dan pemantauan). Terkesan puskesmas tidak mengetahui jenis kegiatan yang seharusnya ada dalam PKPR yaitu konseling.Setelah mengetahui faktor yang paling mempengaruhi rendahnya pemanfaatan PKPR yaitu lemahnya manajemen PKPR dipuskesmas, maka dapat dilakukan tindakan dan langkah perbaikan dalam rangka memperbaiki kinerja dan mutu dengan menerapkan Continuous Improvement sistem manajemen yakni PDCA (Plan, Do, Check, Action). 
Journal of Healthcare Technology and Medicine Vol. 6 No. 2 Oktober 2020

Universitas Ubudiyah Indonesia

e-ISSN : 2615-109X 1139

1. WHO. Adolescent responsive health systems [Internet]. 2015. Available from:

https://www.who.int/maternal_child_adolescent/topics/adolescence/health_ services/en/

2. WHO. Implementation in countries of Global standards for quality of healthcare services for adolescents. 2019.

3. World Health Organization [WHO] -SEARO. Strategic Guidance on Acelerating Actions for Adolescent Health (2018 -2022). 2018. 103 p.

4. Rokom. PMNCH Apresiasi Program Pelayanan Kesehatan Peduli Remaja di Indonesia. Biro Komunikasi dan Pelayanan Masyarakat, Kementerian Kesehatan RI [Internet]. 2019 Sep 22; Available from: http://sehatnegeriku.kemkes.go.id/baca/rilis-

media/20190922/0831769/pmnch-apresiasi-program-pelayanan-kesehatanpeduli-remaja-indonesia/

5. Harianti R. Pendidikan Seks Usia Dini; Teori dan Aplikasi. Yogyakarta: Trans Medika; 2016.

6. Rahayu A. Kesehatan Reproduksi Remaja dan Lansia. 1st ed. Surabaya: Airlangga University Press; 2018.

7. Kemenkes RI. Kesehatan Reproduksi dan Keluarga Berencana. In Pusdik SDM Kesehatan; $2016 . \quad$ Available from: http://bppsdmk.kemkes.go.id/pusdiksdmk/wpcontent/uploads/2017/08/Kespro-dan-KB-Komprehensif.pdf

8. Kementerian Kesehatan RI. Pedoman Standar Nasional Pelayanan Kesehatan Peduli Remaja (PKPR). Jakarta: Direktorat Bina Kesehatan Anak DepKes RI; 2014.

9. BKKBN. Survei demografi dan kesehatan Indonesia 2012: Kesehatan Reproduksi Remaja. In Jakarta; 2012.

10. Satriawan I. Kisah Pilu Remaja yang Hamil di Luar Nikah dan Harus Menjadi Ibu di Usia 16 Tahun. Bangkapos.com [Internet]. 2018; Available from: https://bangka.tribunnews.com/2018/05/13/kisah-pilu-remaja-yanghamil-di-luar-nikah-dan-harus-menjadi-ibu-di-usia-16-tahun

11. Kementerian Kesehatan RI. Pedoman Pelayanan Kesehatan Peduli Remaja di Puskesmas. Jakarta; 2011.

12. Notoadmotjo S. Pendidikan dan Perilaku Kesehatan. Jakarta: Rineka Cipta; 2014.

13. Qanun Aceh No.4 tahun 2010 tentang Kesehatan [Internet]. Banda Aceh; 2010. Available from: file:///C:/Users/New Windows 10/Downloads/null.pdf

14. Kasim F. Dampak Perilaku Seks Berisiko terhadap Kesehatan Reproduksi dan Upaya Penanganannya (Studi tentang Perilaku Seks Berisiko pada Usia Muda di Aceh). J Stud Pemuda [Internet]. 2014;3(1):39-48. Available from: https://jurnal.ugm.ac.id/jurnalpemuda/article/download/32037/19361

15. Langsa DK. Profil Dinas Kesehatan Kota Langsa. langsa; 2019.

16. Erlinawati. laporan PKPR Puskesmas Langsa Kota. langsa; 2019.

17. Gunawan Imam. Metode Penelitian Kualitatif. Jakarta: PT Bumi Aksara; 2015. 
Journal of Healthcare Technology and Medicine Vol. 6 No. 2 Oktober 2020

Universitas Ubudiyah Indonesia

e-ISSN : 2615-109X 1140

18. Moelong LJ. Metode Penelitian. bandung: Remaja Rosda Karya; 1999.

19. Heryana A. Informan dan Pemilihan Informan dalam Penelitian Kualitatif. J Kualitatif. 2018;(December):1-15.

20. Sugiyono. Metode Penelitian Kuantitatif Kualitatif dan R\&D. Surakarta; 2017.

21. Yenita M. 7 Fakta Menarik tentang Perilaku Seksual Remaja yang Harus Anda Tahu. 2020; Available from: http://masyarakatsehat.id/2018/08/13/7fakta-menarik-tentang-perilaku-seksual-remaja-yang-harus-anda-tahu/

22. Laili A dkk. Faktor-Faktor Yang Berhubungan Dengan Praktik Pemanfaatan Pelayanan Kesehatan Peduli Remaja (Pkpr) Oleh Remajadi Wilayah Kerja Puskesmas Bandarharjo Kota Semarang. J Kesehat Masy. 2019;7(1):421-9.

23. Nilatul Izah. Analisis Faktor - Faktor Yang Berpengaruh Terhadap Persepsi Remaja Tentang Praktik Kesehatan Reproduksi Remaja Di SMK YPE Nusantara Slawi. 2018;07:336-40.

24. Muhammad Hasbi. JURNAL KEPERAWATAN TERPADU (Integrated Nursing Journal). EANALISIS Model PEER Educ Metod Adolesc FRIENDLY TERHADAP PENINGKATAN Pengetah DAN SIKAP REMAJA TENTANG PERILAKU SEKSUAL BERISIKO. 2019;9698(1):65-75.

25. Kemenkes RI. Pelayanan Kesehatan Peduli Remaja (PKPR) Bagi Tenaga Kesehatan. Jakarta; 2011.

26. Afrianti N, Tahlil T, Studi P, Keperawatan M, Keperawatan F, Kuala US, et al. Analisis Implementasi Program Pelayanan Kesehatan Peduli Remaja (PKPR). J Ilmu Keperawatan. 2018;5(2):15-27.

27. Kristina Y. Faktor-faktor yang Mempengaruhi Pemanfaatan Pelayanan Kesehatan Reproduksi Remaja di Kota Jayapura. 2017;9(2):63-73.

28. Indah Mauludiyah MME. Analisis Pelaksanaan Pelayanan Kesehatan Peduli Remaja diwilayah Kerja Dinas Kesehatan Kabupaten Malang. Bull Kalmyk Inst Humanit Russ Acad Sci. 2017;33(5):82-92.

29. Sri Suciana. Evaluasi Pelaksanaan Program Kesehatan Peduli Remaja ( PKPR ) Di Sekolah Menengah Atas Kota Bukit Tinggi. 2019;4(2):76-85.

30. Friskarini K, Manalu HS. Implementasi Program Pelayanan Kesehatan Peduli Remaja (Pkpr) Di Tingkat Puskesmas Dki Jakarta. J Ekol Kesehat. 2016;15(1):66-75.

31. Ruwayda N. FAKTOR-FAKTOR YANG BERHUBUNGAN DENGAN PEMANFAATAN PELAYANAN KESEHATAN REPRODUKSI OLEH REMAJA DI SMPN 19 WILAYAH KERJA PUSKESMAS AUR DURI KOTA JAMBI. J Bahana Kesehat Masy Vol1 No2Edisi Novemb ISSN 2580-0590. 2017; Vol.1.

32. Direktorat Bina Kesehatan Masyarakat. Pedoman Perencanaan Program Kesehatan Remaja Bagi Tim Kabupaten/Kota. Jakarta: Kementrian Kesehatan RI; 2011.

33. Lestari S. Pelajaran Kesehatan Reproduksi ditolak MK. BBC News Indonesia [Internet]. 2015 Nov; Available from: https://www.bbc.com/indonesia/berita_indonesia/2015/11/151102_indonesi a_pendidikanseks

34. Mulinda R. Penataan Pendidikan Profesional Konselor dan Layanan 
Journal of Healthcare Technology and Medicine Vol. 6 No. 2 Oktober 2020

Universitas Ubudiyah Indonesia

e-ISSN : 2615-109X 1141

Bimbingan dan Konseling Dalam Jalur Pendidikan Formal. Available from: https://www.academia.edu/33105047/DUKUNGAN_SISTEM_FIXXX

35. Ernawati $H$. Pengetahuan kesehatan reproduksi remaja di daerah pedesaan. 2018;02(01). 